Article

\title{
Hepatoprotection by Traditional Essence of Ginseng against Carbon Tetrachloride-Induced Liver Damage
}

\author{
Yi-Ju Hsu ${ }^{\dagger}$, Chao-Yun Wang ${ }^{\dagger}$, Mon-Chien Lee and Chi-Chang Huang * \\ Graduate Institute of Sports Science, National Taiwan Sport University, Taoyuan 33301, Taiwan; \\ ruby780202@ntsu.edu.tw (Y.-J.H.); 1080213@ntsu.edu.tw (C.-Y.W.); 1061304@ntsu.edu.tw (M.-C.L.) \\ * Correspondence: john5523@ntsu.edu.tw; Tel.: +886-3-3283201 (ext. 2409) \\ + These authors contributed equally to this work.
}

Received: 10 September 2020; Accepted: 19 October 2020; Published: 21 October 2020

\begin{abstract}
The peroxide produced in the lipid metabolic process attacks liver cells and causes liver injury. Ginsenosides have been shown to have anti-oxidation abilities and to mend myocardial damage. This study evaluated the effect of traditional ginseng essence (TEG) in preventing chemical liver damage induced by carbon tetrachloride $\left(\mathrm{CCl}_{4}\right)$. Forty 8-week-old male Sprague Dawley (SD) rats were divided into five groups: control, liver injury $\left(\mathrm{CCl}_{4}\right)$, and TEG by oral gavage at 0.074 , 0.149 , or $0.298 \mathrm{~g} / \mathrm{kg} /$ day for nine weeks. Liver injury biochemical indicators, antioxidant enzyme activity, and lipid contents in liver tissues were evaluated. The liver appearance was observed, and histopathological tests were conducted to estimate whether TEG-antagonized oxidants further ameliorated liver injury. The results show that, after supplementation of TEG for nine consecutive weeks and $\mathrm{CCl}_{4}$-induced liver injury for eight weeks, the levels of liver injury biochemical indicators in animal serum decreased significantly, and, in liver tissue, antioxidant activity was significantly improved and accumulation of lipids was decreased. Pathological sections exhibited reduced liver lipid accumulation and fibrosis. As discussed above, TEG can increase the antioxidant capacity in the liver and the maintenance of hepatocyte function, protecting the liver from chemical injury and improving healthcare.
\end{abstract}

Keywords: ginsenosides; hepatoprotection; liver injury; anti-oxidant

\section{Introduction}

An irregular lifestyle may cause abnormal lipid metabolism in the body. Converting lipophilic xenobiotics to hydrophilic forms leads to incomplete pharmacological or biological activity and conversion effects. The harmful reactive intermediates produced, such as free radicals and redox-active reactants, can induce metabolic pressure [1]. Metabolic pressure or an inflammatory response may damage liver cells and even cause steatosis and cirrhosis [2]. In hepatic stellate cells, collagen synthesis, which plays a direct causative role in liver fibrogenesis, is triggered by lipid peroxidation caused by oxidative stress [3]. Above all, liver cell damage is closely correlated to oxidative stress.

A $\mathrm{CCl}_{4}$-induced liver injury model has been used to evaluate the chemical liver injury. The mechanism occurs during liver metabolism, wherein cytochrome P450 (CYP) enzymes in $\mathrm{CCl}_{4}$ form the trichloromethyl radical $\left(\mathrm{CCl}_{3}\right)$ [4]. This process impairs crucial cellular processes and induces extensive cell damage and apoptosis. In hepatic apoptosis and fibrosis, the synthesis of cellular phospholipids refers to the incorporation of phospholipids into lipoproteins, leading to the accumulation of triglycerides [5].

Ginseng is one of the few medicinal plants that can be eaten from root to leaf. The active ingredients of ginseng are more than 30 ginsenosides. These ginsenosides can be classified into two main groups: glycosides of 20(S)-protopanaxadiol (Rb1, Rb2, Rc, Rd, Rg3, and Rh2) and 
glycosides of 20(S)-protopanaxatriol (Re, Rf, Rg1, Rg2, Rh1, and R1) [6]. Panax ginseng (G-115) and P. quinquefolius (CNT-2000) are the most widely used breeds in medicinal products [7]. One study used high-performance liquid chromatography (HPLC) to analyze these two different breeds of ginseng and found that the major ingredients of $P$. ginseng are $\mathrm{Rb} 1, \mathrm{Rb} 2, \mathrm{Rc}, \mathrm{Rg} 1$, and $\mathrm{Re}$, and that $P$. quinquefolius has higher concentrations of $\mathrm{Rb} 1$ and $\mathrm{Re}$ [8]. These medicinal ingredients have multiple biotransformation effects. They can reduce inflammation and oxidative stress [9]. Another study showed that Tibetan Rhodiola rosea $\mathrm{L}$ can reduce oxidative stress and protect hepatic cells [10]. In particular, in one previous study, ginsenoside $\mathrm{Rg} 2$ was shown to modulate the protein p53 in cell apoptosis and, thereby, improve vascular dementia or other ischemic injury [11]. The antioxidant mechanism of ginsenosides may reduce oxidative stress and effectively improve liver injury. In this study, we investigated the effects of different doses of traditional essence of ginseng (TEG) supplements on the liver cell and functional damage after $\mathrm{CCl}_{4}$-induced liver injury in rats.

\section{Materials and Methods}

\subsection{Materials}

Traditional essence of ginseng (TEG) derived from P. ginseng (Asian ginseng) and P. quinquefolius (American ginseng) manufactured with good manufacturing practices (GMP) was purchased from LAO XIE ZHEN Co., Ltd. (Taipei City, Taiwan) and stored at $-20^{\circ} \mathrm{C}$ for the following experiments. The dosage of TEG for rats was calculated based on a human with a body weight of $60 \mathrm{~kg}$. The metabolic conversion based on body area for the rats was 6.2 , and the $1 \mathrm{X}$ daily-recommended dose was calculated as follows: $1.44(\mathrm{~g}) / 60(\mathrm{~kg})=0.024 \times 6.2=$ a rat dose of $0.149 \mathrm{~g} / \mathrm{kg}$. This formula is in line with guidelines from the US Food and Drug Administration.

The content of the TEG, which included ginsenoside Rg2, was determined by a high-performance liquid chromatography (HPLC) method described previously [12] with some modification. A Waters 600 pump system with a 717 plus HPLC autosampler and a Waters 2996 tunable absorbance detector were used to analyze the ginsenoside $\mathrm{Rg} 2$ in a Cosmosil $5 \mathrm{C}_{18}$-MS-II column (i.d. $4.6 \times 250 \mathrm{~mm}$ ) at $203 \mathrm{~nm}$. A mixture of acetonitrile and $\mathrm{H}_{2} \mathrm{O}$ /potassium dihydrogen phosphate of $1000 \mathrm{~mL}: 2.72 \mathrm{~g}$ was used as the mobile phase at a flow rate of $1 \mathrm{~mL} / \mathrm{min}$ and an injection volume of $20 \mu \mathrm{L}$.

\subsection{Animals and Treatment}

Male eight-week-old Sprague Dawley (SD) rats (BioLASCO, Yi-Lan, Taiwan) weighing around $250 \mathrm{~g}$ were housed within cages at $22 \pm 2{ }^{\circ} \mathrm{C}$ and $60 \% \pm 10 \%$ relative humidity with a $12 \mathrm{~h}$ dark/light cycle, with ad libitum access to food (No. 5001, PMI Nutrition International, Brentwood, MO, USA) and reverse osmosis water. The experimental protocol was approved by the Animal Care and Use Committee (IACUC) No. 10,805 for the ethical use of animals in experiments at the National Taiwan Sport University.

Forty SD rats were randomized into five groups ( $n=8$ per group): olive oil (CON), $\mathrm{CCl}_{4}$ per oral (p.o.), and dietary supplementation with TEG doses of $0.074,0.149$, and $0.289 \mathrm{mg} / \mathrm{kg}$ body weight (BW) plus $\mathrm{CCl}_{4}$ (TEG-0.5X, TEG-1X, and TEG-2X, respectively). The detailed experimental design is illustrated in Figure 1. After 1 week of olive oil (CON and $\mathrm{CCl}_{4}$ groups) or TEG treatment, the $\mathrm{CCl}_{4}$, TEG-0.5X, TEG-1X, and TEG-2X groups were orally administrated with $\mathrm{CCl}_{4}$ dissolved in olive oil twice a week $\left(20 \% \mathrm{CCl}_{4}\right.$ in olive oil, $\left.0.5 \mathrm{~mL} / \mathrm{rat}\right)$ while the control group (CON) group was orally administrated with olive oil only $(0.5 \mathrm{~mL} / \mathrm{rat})$. Moreover, the $0.5 \mathrm{X}, 1 \mathrm{X}$, and $2 \mathrm{X}$ groups were continuously treated with TEG, whereas the $\mathrm{CON}$ and $\mathrm{CCl}_{4}$ groups were treated with olive oil every day. TEG was treated after $1 \mathrm{~h}$ of $\mathrm{CCl}_{4}$ administration to avoid the interaction with $\mathrm{CCl}_{4}$ [13]. The purchase and storage of $\mathrm{CCl}_{4}$ followed the Chemical Management System of National Taiwan Sport University for toxic chemical substances. The food and water intake were monitored daily and the rats were weighed to determine their body weight every week. 


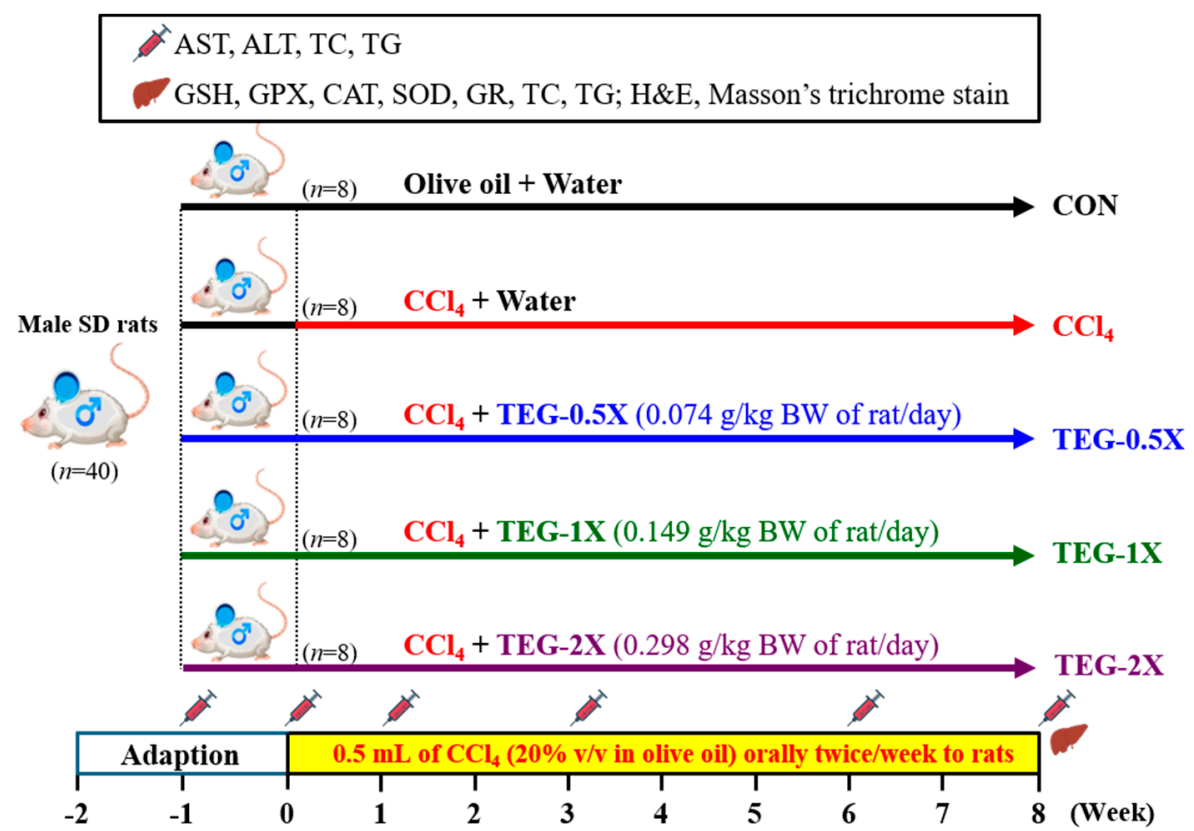

Figure 1. Experimental design. Forty Sprague Dawley (SD) rats were randomized into five groups ( $n=8$ per group): olive oil $(\mathrm{CON})$, carbon tetrachloride $\left(\mathrm{CCl}_{4}\right)$ per oral (p.o.), and dietary supplementation with a traditional essence of ginseng (TEG) doses of $0.074,0.149$, and $0.289 \mathrm{mg} / \mathrm{kg}$ body weight (BW) plus $\mathrm{CCl}_{4}$ (TEG-0.5X, TEG-1X, and TEG-2X, respectively). CON: Healthy rats orally received a volume of water equivalent to body weight (BW). The $\mathrm{CCl}_{4}, \mathrm{TEG}-0.5 \mathrm{X}, \mathrm{TEG}-1 \mathrm{X}$, and TEG-2X groups were orally administrated with $\mathrm{CCl}_{4}$ dissolved in olive oil twice a week $\left(20 \% \mathrm{CCl}_{4}\right.$ in olive oil, $0.5 \mathrm{~mL} / \mathrm{rat})$, while the CON group was orally administrated with olive oil only $(0.5 \mathrm{~mL} / \mathrm{rat})$. $\mathrm{CON}$, control group. $\mathrm{CCl}_{4}, \mathrm{CCl}_{4}$ administration only. TEG-0.5X, $\mathrm{CCl}_{4}$ administration with 0.5 times the daily recommended dosage of the TEG. TEG-1X, $\mathrm{CCl}_{4}$ administration with daily recommended dosage of the TEG. TEG-2X, $\mathrm{CCl}_{4}$ administration with 2 times the daily recommended dosage of the TEG. Liver ( ) blood ( AST: aspartate transaminase. ALT: alanine transaminase. TC: total cholesterol. TG: triglyceride. GSH: glutathione. GPX: glutathione peroxidase. SOD: superoxide dismutase. CAT: catalase. GR: glutathione reductase.

\subsection{Clinical Biochemical and Hematological Profile Assay}

The rats fasted overnight for 8-12 h before blood was collected. Four hours after the ginseng supplement was consumed, blood samples were drawn from the tail veins of the rats. At the end of the experiment (eighth week), the rats were sacrificed by $95 \% \mathrm{CO}_{2}$ exposure and their blood and organs were collected for analysis. The collected blood samples were centrifuged at $4500 \mathrm{rpm}$ for $15 \mathrm{~min}$ at $4{ }^{\circ} \mathrm{C}$. Serum biochemical analyses of aspartate transaminase (AST) and alanine transaminase (ALT) activities, albumin, and total cholesterol (TC) and triacylglycerol (TG) levels were conducted with a 7150 Automatic blood chemistry analyzer (Hitachi Co., Ltd., Tokyo, Japan).

\subsection{Hepatic Antioxidant Levels}

Liver tissue samples of $30 \mathrm{mg}$ were collected and rinsed in 5-10 mL of cold buffer (i.e., phosphate-buffered saline) and centrifuged at 10,000 $\mathrm{g}$ for $15 \mathrm{~min}$ at $4{ }^{\circ} \mathrm{C}$ to remove blood cells and clots for a subsequent test. Biochemical kits (Cayman Chemical Co., Ann Arbor, MI, USA) were used to determine the hepatic reduced glutathione (GSH) concentration, glutathione peroxidase (GPX), glutathione reductase (GR), superoxide dismutase (SOD), and catalase (CAT) activities.

\subsection{Hepatic Lipid Profile Assay}

Liver tissues ( $350 \mathrm{mg}$ ) were homogenized in $2 \mathrm{~mL}$ of cold buffer (i.e., chloroform/isopropanol/NP40 $=7: 11: 0.1)$ and the samples were centrifuged at $10,000 \times g$ for $10 \mathrm{~min}$ at $4{ }^{\circ} \mathrm{C}$ for analysis. After removal 
of the supernatants, samples were remixed with a diluting buffer ( $50 \mathrm{mM}$ sodium phosphate, $\mathrm{pH}$ 7.2). The remixed hepatic triacylglycerol (TG) was determined using a triacylglycerol fluorometric assay kit (item number: 10010303, Cayman Chemical Co., MI, USA).

The total cholesterol (TC) concentration was determined using a cholesterol fluorometric assay kit (item number: 10007640, Cayman Chemical Co., MI, USA). For this test, $100 \mu \mathrm{L}$ of samples were added to wells, and the plate cover was removed to initiate the reactions by adding $50 \mu \mathrm{L}$ of a prepared assay cocktail to all of the wells. Liver extractions were mixed well with the reagent buffer and the absorbance value was measured under optical density (OD) of $560 \mathrm{~nm}$.

\subsection{Pathological Examination of Liver Tissues}

After being cleaned with saline, the liver tissue was collected immediately and maintained at $-80^{\circ} \mathrm{C}$ until analysis. One sample of liver tissue $(1 \mathrm{~cm} \times 1 \mathrm{~cm})$ was cut from the largest right lobe and fixed in $40 \mathrm{~g} / \mathrm{L}$ formaldehyde solution for histology. Hematoxylin-eosin dye (H\&E stain) and Masson's trichrome were used to stain the liver tissue for histological examinations.

The H\&E stain was used to evaluate chronic liver damage, including hepatocyte gross necrosis, fatty change, and fibrosis. Levels of steatosis and inflammatory cell infiltration were assessed by semi-quantitative histological evaluation. The scale of liver damage ranged from 0 to 4 , where $0=$ absent, $1=$ trace, $2=$ mild, $3=$ moderate, and $4=$ severe [14]. Masson's trichrome stain was used to evaluate collagenous fibers.

\subsection{Statistics Analysis}

Values are presented as mean $\pm \mathrm{SD}$. To evaluate differences between groups, one-way analysis of variance (ANOVA) was used. A Cochran-Armitage test with SAS 9.0 software (SAS Inst., Cary, NC, USA) was used to estimate the dose effect with $p$-values of less than 0.05 indicating a statistical significance.

\section{Results}

\subsection{Content of Ginsenoside Rg2 in TEG}

The retention time of ginsenoside $\mathrm{Rg} 2$ was $44.1 \mathrm{~min}$ (Figure 2). Based on the calibration curve, the content of total ginsenoside Rg2 in the TEG was $0.88 \mathrm{mg} / \mathrm{g}$.

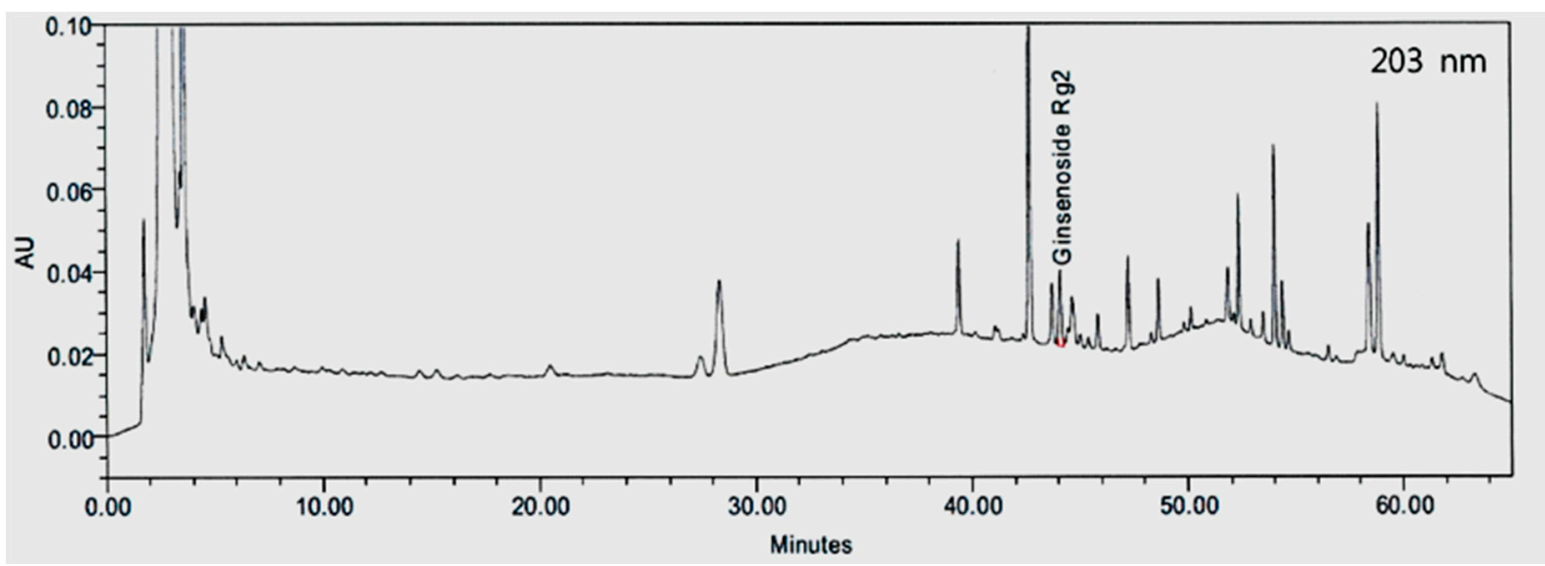

Figure 2. High-performance of liquid chromatography (HPLC) chromatogram of ginsenoside Rg2 in traditional essence of ginseng (TEG).

\subsection{Effects of TEG on Blood Parameters in Rats with $\mathrm{CCl}_{4}$-Induced Liver Damage}

Aspartate transaminase (AST) and alanine transaminase (ALT) activities are liver function markers. After nine weeks of supplementation with TEG and eight weeks of $\mathrm{CCl}_{4}$-induced liver 
injury, the changes in the liver function biochemical index in the blood of rats in each group were examined. The AST activities in the serum of the CON, $\mathrm{CCl}_{4}, \mathrm{TEG}-0.5 \mathrm{X}, \mathrm{TEG}-1 \mathrm{X}$, and TEG-2X groups were $95 \pm 8,530 \pm 23,457 \pm 24,441 \pm 14$, and $426 \pm 19(\mathrm{U} / \mathrm{L})$, respectively. The $1 \mathrm{X}$ and TEG-2X groups supplemented with TEG exhibited dose trends. The AST activities were significantly lower, by approximately $13.83 \%, 16.95 \%$, and $19.75 \%$ in these groups, respectively, relative to the $\mathrm{CCl}_{4}$ group (Figure 3A) $(p<0.0001)$. The changes in the serum ALT activities in the CON, CCl $, \mathrm{TEG}-0.5 \mathrm{X}, \mathrm{TEG}-1 \mathrm{X}$, and TEG-2X groups were $43 \pm 7,170 \pm 15,144 \pm 19,132 \pm 16$, and $117 \pm 12$ (U/L), respectively. The ALT activities of the TEG-0.5X, TEG-1X, and TEG-2X groups exhibited dose trends, which were significantly lower than in the $\mathrm{CCl}_{4}$ group by about $15.29 \%(p=0.0008), 22.35 \%$, and $31.18 \%$ (relative to the $\mathrm{CCl}_{4}$ group), respectively (Figure $3 \mathrm{~B})(p<0.0001)$. Statistical analysis showed no significant differences in albumin concentration among the five groups.

(A)

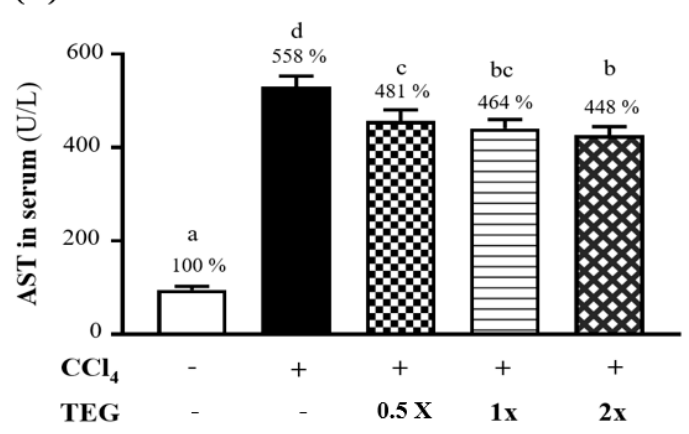

(C)

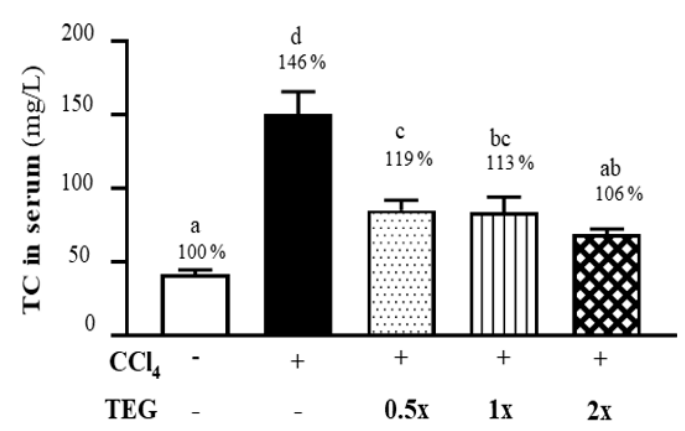

(B)

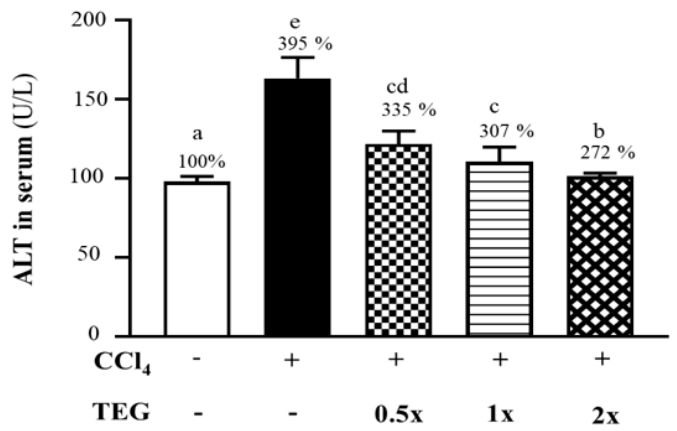

(D)

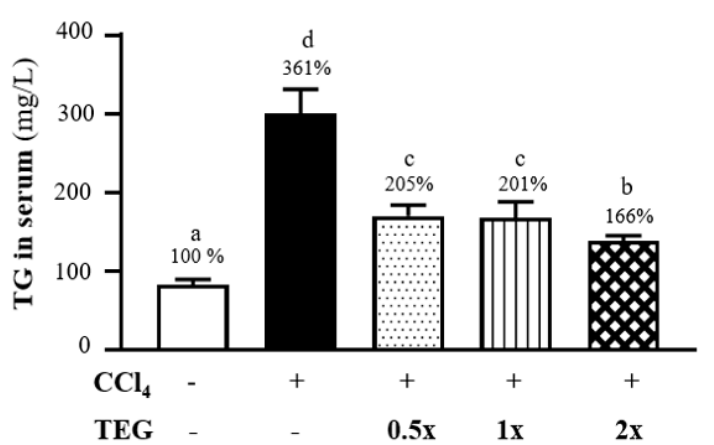

Figure 3. Effect of traditional essence of ginseng (TEG) supplementation on blood parameters in (A) aspartate transaminase (AST), (B) alanine transaminase (ALT), (C) total cholesterol (TC), and (D) triglyceride (TG) with carbon tetrachloride $\left(\mathrm{CCl}_{4}\right)$-induced liver damage at the eighth week. Data are presented as mean $\pm \mathrm{SD}$ for $n=8$ rats in each group. Different letters $(\mathrm{a}, \mathrm{b}, \mathrm{c}, \mathrm{d}, \mathrm{e})$ mean significant difference at $p<0.01$ according to one-way ANOVA.

Concentrations of plasma total cholesterol (TC) and triglyceride (TG) have a high correlation with chronic liver disease [15]. The serum TC concentrations in the CON, $\mathrm{CCl}_{4}, \mathrm{TEG}-0.5 \mathrm{X}, \mathrm{TEG}-1 \mathrm{X}$, and TEG-2X groups were $68 \pm 4,99 \pm 6,81 \pm 7,77 \pm 8$, and $72 \pm 7(\mathrm{mg} / \mathrm{dL})$, respectively, which is significantly lower, by $27 \%, 33 \%$, and $40 \%$, when compared to the $\mathrm{CCl}_{4}$ group $(p<0.0001)$. The TG concentrations in the CON, CCl 4 , TEG-0.5X, TEG-1X, and TEG-2X groups were $83 \pm 6,300 \pm 31$, $170 \pm 14,167 \pm 21$, and $138 \pm 7(\mathrm{mg} / \mathrm{dL})$, respectively, which is significantly lower, by $43.33 \%, 44.38 \%$, and $53.88 \%$ in the TEG-0.5X, TEG- $1 \mathrm{X}$, and TEG-2X groups, respectively, than in the $\mathrm{CCl}_{4}$ group (Figure $3 C)(p<0.0001)$.

The intake of $\mathrm{CCl}_{4}$ was the main reason for the increase in the liver AST, ALT, TC, and TG contents of the animals, and the supplementation of $0.5 \mathrm{X}, 1 \mathrm{X}$, and $2 \mathrm{X}$ doses of TEG for nine weeks effectively reduced the effects of increased liver AST, ALT, TC, and TG contents caused by $\mathrm{CCl}_{4}$-induced liver injury. 


\subsection{TEG Effects on Hepatic Antioxidative Parameters in Rats with $\mathrm{CCl}_{4}$ —Induced Liver Damage}

Table 1 shows the activities of GSH, GPX, GR, SOD, and CAT with $\mathrm{CCl}_{4}$-induced liver damage at the eighth week. The liver GSH content in the $\mathrm{CCl}_{4}$ group was significantly reduced by $10.56 \%$ $(p=0.0004)$ after 8 weeks of $\mathrm{CCl}_{4}$-induced liver injury compared with the $\mathrm{CON}$ group. However, in the TEG-0.5X, TEG-1X, and TEG-2X groups, the GSH contents were significantly increased about 1.12 -fold $(p=0.0004), 1.11$-fold $(p=0.0006)$, and 1.13-fold compared with the $\mathrm{CCl}_{4}$ group $(p=0.0001)$. GPX activity in the TEG-0.5X, TEG-1X, and TEG-2X groups significantly increased about 1.09-fold $(p=0.0003), 1.10$-fold $(p=0.0002)$, and 1.25 -fold above that of the $\mathrm{CCl}_{4}$ group $(p<0.0001)$. GR activity of the CON group had no significant difference with the TEG-0.5X and TEG-1X groups. In these groups, the GR activity was about 1.53-fold higher than that of the $\mathrm{CCl}_{4}$ group $(p<0.0001)$. Additionally, in the TEG-2X group, it was significantly higher by about 1.61-fold $(p<0.0001)$ than that in the $\mathrm{CCl}_{4}$ group, and this group had even higher activity than the other four groups. Hepatic SOD activity in the CON and TEG-2X groups was significantly increased about 1.20-fold when compared with the $\mathrm{CCl}_{4}$ group $(p=0.0027)$. Moreover, CAT activity in the TEG-0.5X, TEG-1X, and TEG-2X groups was about 1.08 -fold to 1.12-fold higher than that in the $\mathrm{CCl}_{4}$ group. The TEG-2X group had the highest level among the TEG groups. It was nearly equal to that of the CON group.

Table 1. Effects of traditional ginseng essence (TEG) on hepatic antioxidative parameters in rats with carbon tetrachloride $\left(\mathrm{CCl}_{4}\right)$-induced liver damage at the eighth week.

\begin{tabular}{|c|c|c|c|c|c|}
\hline \multirow{2}{*}{ Group } & GSH & GPX & GR & SOD & CAT \\
\hline & $(\mu \mathrm{M} / \mathrm{mg})$ & $(\mathrm{nmol} / \mathrm{min} / \mathrm{mg})$ & (nmol/min/mg) & (U/mg) & (nmol/min/mg) \\
\hline $\mathrm{CON}$ & $1.61 \pm 0.10^{b}$ & $11.68 \pm 0.62^{d}$ & $14.06 \pm 0.41^{\mathrm{b}}$ & $0.082 \pm 0.023^{b}$ & $33.08 \pm 0.48^{\mathrm{d}}$ \\
\hline $\mathrm{CCl}_{4}$ & $1.44 \pm 0.06^{\mathrm{a}}$ & $8.86 \pm 0.27^{a}$ & $9.18 \pm 0.69^{a}$ & $0.061 \pm 0.005^{\mathrm{a}}$ & $28.65 \pm 0.32^{a}$ \\
\hline TEG-0.5X & $1.61 \pm 0.08^{b}$ & $9.71 \pm 0.43^{b}$ & $14.06 \pm 0.57^{b}$ & $0.062 \pm 0.004^{\mathrm{a}}$ & $30.87 \pm 0.67^{b}$ \\
\hline TEG-1X & $1.60 \pm 0.07^{b}$ & $9.75 \pm 0.25^{b}$ & $14.15 \pm 0.68^{b}$ & $0.066 \pm 0.003^{\mathrm{a}}$ & $30.84 \pm 0.32^{b}$ \\
\hline TEG-2X & $1.62 \pm 0.11^{b}$ & $11.11 \pm 0.45^{c}$ & $14.78 \pm 0.49^{c}$ & $0.079 \pm 0.007^{b}$ & $32.09 \pm 0.57^{c}$ \\
\hline
\end{tabular}

Values are presented as mean \pm SD for $n=8$. Values in a column with the same letters $(\mathrm{a}, \mathrm{b}, \mathrm{c}, \mathrm{d})$ are not significantly different at $p<0.05$ according to one-way ANOVA with Cochran-Armitage test and trend analysis. $\mathrm{CON}$, control group. $\mathrm{CCl}_{4}, \mathrm{CCl}_{4}$ administration only. TEG-0.5X, $\mathrm{CCl}_{4}$ administration with 0.5 times the daily recommended dosage of TEG. TEG-1X, $\mathrm{CCl}_{4}$ administration with daily recommended dosage of TEG. TEG-2X, $\mathrm{CCl}_{4}$ administration with two times the daily recommended dosage of TEG. GSH: glutathione. GPX: glutathione peroxidase. SOD: superoxide dismutase. CAT: catalase. GR: glutathione reductase.

\subsection{Effects of TEG on Hepatic Lipid Profiles in Rats with $\mathrm{CCl}_{4}$-Induced Liver Damage}

The changes in the hepatic TC content in the CON, CCl 4 , TEG-0.5X, TEG-1X, and TEG-2X groups were $1.96 \pm 0.07,3.27 \pm 0.26,2.44 \pm 0.16,2.21 \pm 0.19$, and $2.03 \pm 0.04(\mathrm{mg} / \mathrm{g}$ wet liver), respectively. The hepatic TC contents of the TEG-0.5X, TEG-1X, and TEG-2X groups were significantly lower, by approximately $25.42 \%, 32.38 \%$, and $37.81 \%$, respectively, than in the $\mathrm{CCl}_{4}$ group $(p<0.0001)$ (Figure 4A). The hepatic TG levels in the CON, CCl, TEG-0.5X, TEG-1X, and TEG-2X groups were $13.8 \pm 1.1,24.6 \pm 1.2,23.3 \pm 0.8,21.8 \pm 0.5$, and $18.3 \pm 1.0(\mathrm{mg} / \mathrm{g}$ wet liver), respectively. In the TEG-0.5X, TEG-1X, and TEG-2X groups, hepatic TC contents were significantly lower, by about $5.36 \%(p=0.0077)$, $11.52 \%(p<0.0001)$, and $25.65 \%$, respectively, than in the $\mathrm{CCl}_{4}$ group $(p<0.0001)$ (Figure $\left.4 \mathrm{~B}\right)$.

\subsection{Effects of TEG on Weight of Liver Changes in Rats with $\mathrm{CCl}_{4}$-Induced Liver Damage}

Changes in the relative liver weights of the animals in the CON, CCl 4 , TEG-0.5X, TEG-1X, and TEG-2X groups were $2.80 \pm 0.36,3.62 \pm 0.56,3.57 \pm 0.47,3.28 \pm 0.38$, and $2.98 \pm 0.29(\%)$, respectively. Statistical analysis showed that the relative liver weights of the $\mathrm{CCl}_{4}$, TEG-0.5X, and TEG-1X groups increased by 1.29-fold ( $p=0.0007), 1.27$-fold, $(p=0.0011)$ and 1.17-fold $(p=0.0295)$, respectively, after 8 weeks of $\mathrm{CCl}_{4}$-induced liver injury. The relative liver weight of the TEG-2X group was significantly lower, by about $17.49 \%$, relative to that of the $\mathrm{CCl}_{4}$ group $(p=0.0072)$ (Table 2$)$. 
(A)

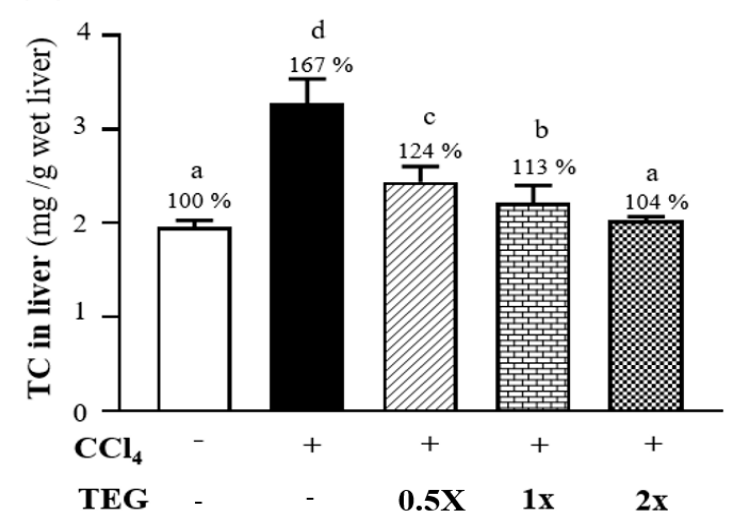

(B)

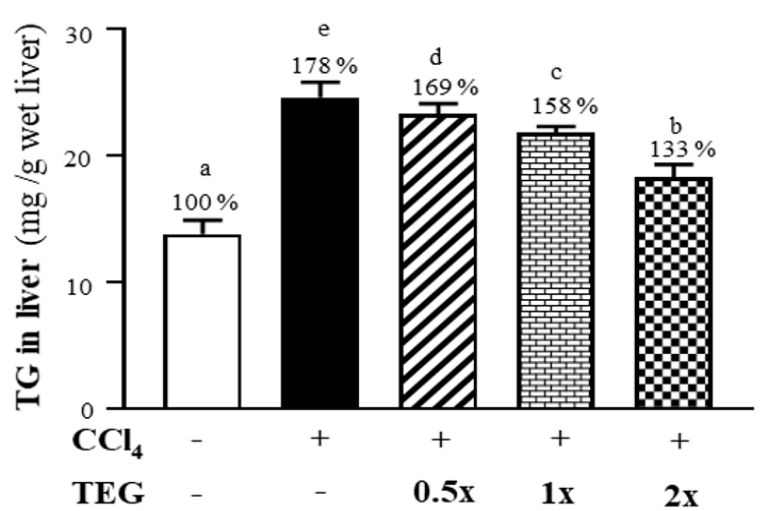

Figure 4. Effect of traditional essence of ginseng (TEG) supplementation on blood parameters: (A) total cholesterol (TC) in liver contents and (B) triglyceride (TG) in liver contents with carbon tetrachloride $\left(\mathrm{CCl}_{4}\right)$-induced liver damage at the eighth week. Data are presented as mean $\pm \mathrm{SD}$ for $n=8$ rats in each group. Different letters $(\mathrm{a}, \mathrm{b}, \mathrm{c}, \mathrm{d}, \mathrm{e})$ mean significant difference at $p<0.01$ according to one-way ANOVA.

Table 2. Absolute weight and relative weight of liver changes in each group of rats after 9 weeks of supplementation with traditional essence of ginseng (TEG) and 8 weeks of carbon tetrachloride $\left(\mathrm{CCl}_{4}\right)$-induced liver injury.

\begin{tabular}{ccc}
\hline \multirow{2}{*}{ Group } & Liver & Relative Liver \\
\cline { 2 - 3 } & $\mathbf{( g )}$ & $\mathbf{( \% )}$ \\
\hline CON & $13.6 \pm 1.2^{\mathrm{a}}$ & $2.80 \pm 0.36^{\mathrm{a}}$ \\
CCl $_{\mathbf{4}}$ & $16.5 \pm 2.5^{\mathrm{c}}$ & $3.62 \pm 0.56^{\mathrm{c}}$ \\
TEG-0.5X $^{\mathrm{c}}$ & $16.6 \pm 2.0^{\mathrm{c}}$ & $3.57 \pm 0.47^{\mathrm{c}}$ \\
TEG-1X & $15.6 \pm 2.0^{\mathrm{bc}}$ & $3.28 \pm 0.38^{\mathrm{bc}}$ \\
TEG-2X & $14.5 \pm 1.4^{\mathrm{ab}}$ & $2.98 \pm 0.29^{\mathrm{ab}}$
\end{tabular}

Values are the mean $\pm \mathrm{SD}$ for $n=8$. Values in a column with the same letters $(\mathrm{a}, \mathrm{b}, \mathrm{c})$ did not significantly differ at $p<0.05$, according to one-way ANOVA with the Cochran-Armitage test and trend analysis. CON, control group. $\mathrm{CCl}_{4}, \mathrm{CCl}_{4}$, administration only. TEG-0.5X, $\mathrm{CCl}_{4}$ administration with 0.5 times the daily recommended dosage of TEG. TEG-1X, $\mathrm{CCl}_{4}$ administration with daily recommended dosage of TEG. TEG-2X, $\mathrm{CCl}_{4}$ administration with two times the daily recommended dosage of TEG.

\subsection{Subacute Histopathology Evaluation and Effect of TEG against $\mathrm{CCl}_{4}$-Induced Hepatotoxicity}

Macroscopic observation of liver tissues (Figure 5A) in the $\mathrm{CCl}_{4}$ group showed a rough liver surface with nodular protrusions of different sizes that were brown in appearance and firm to the touch. In the TEG-0.5X, TEG-1X, and TEG-2X groups, the liver surfaces were smooth with flat nodular protrusions that were dark red in appearance and soft to the touch.

H\&E stain histopathological (Figure 5B) examinations showed significant increases in fatty changes, bile duct hyperplasia, inflammatory cell infiltration, necrosis, and fibrosis $(p<0.05)$ in the $\mathrm{CCl}_{4}$ group. In contrast to the $\mathrm{CCl}_{4}$ group, the $0.5 \mathrm{X}, 1 \mathrm{X}$, and TEG-2X groups had significant decreases in fatty changes, bile duct hyperplasia, inflammatory cell infiltration, and necrosis $(p<0.05)$. Moreover, the TEG-2X group showed significant decreases in fibrosis $(p<0.05)$ (Table 3$)$. These data indicate that $\mathrm{CCl}_{4}$ induced steatosis, necrosis, inflammation, and fibrosis in the rats. However, the supplementation of TEG improved the histology of $\mathrm{CCl}_{4}$-treated rat livers, especially in the TEG-2X group for inhibition of fibrosis. The results also showed that the $\mathrm{CCl}_{4}$-treated group reflected more collagen fiber, and the phenomenon of accumulation was noted in Masson's trichrome stain (Figure 5C). However, we found that TEG supplementation reduced the generation and accumulation of collagen fiber. 
(A)
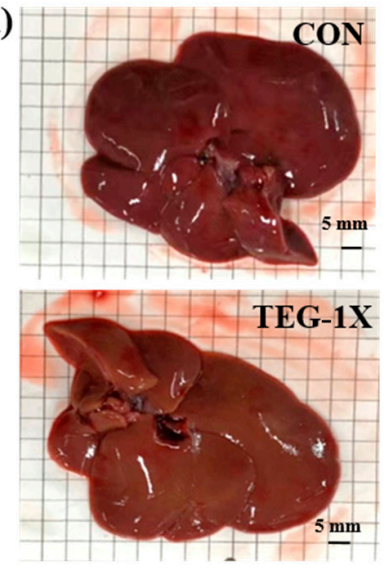

(B)
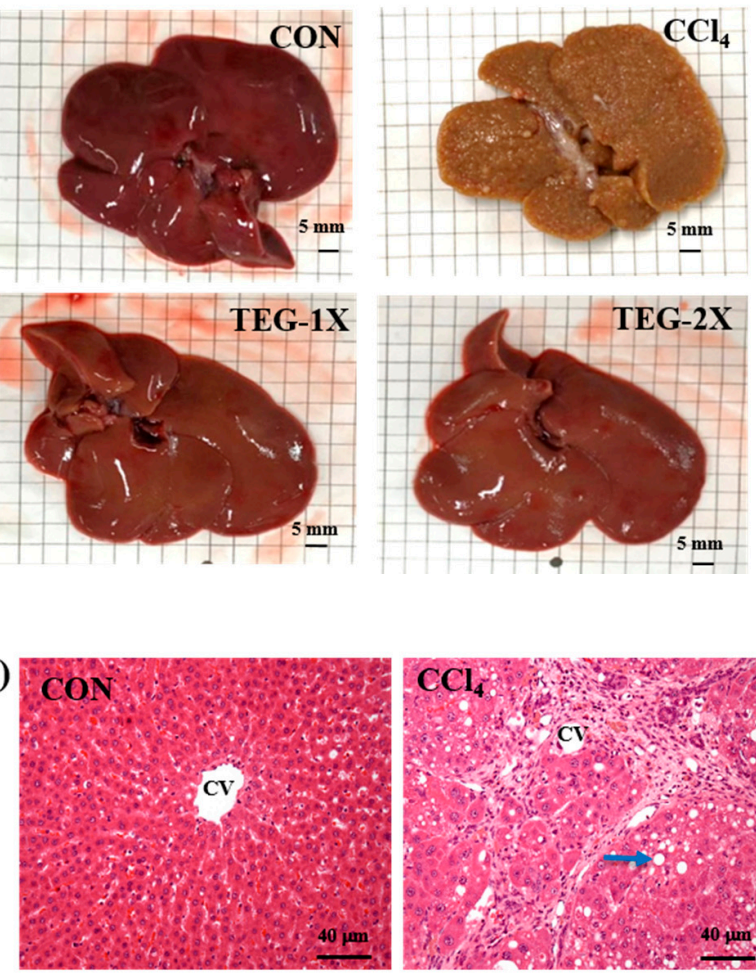
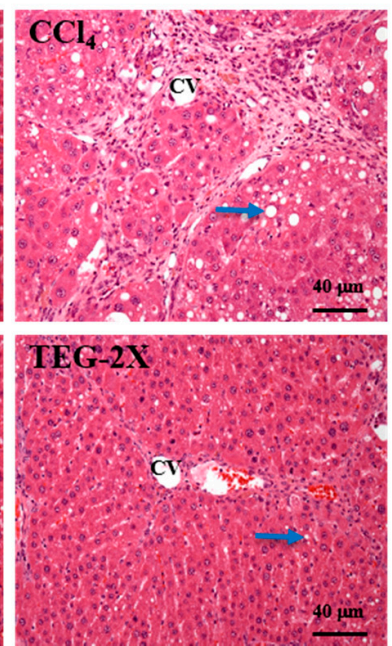
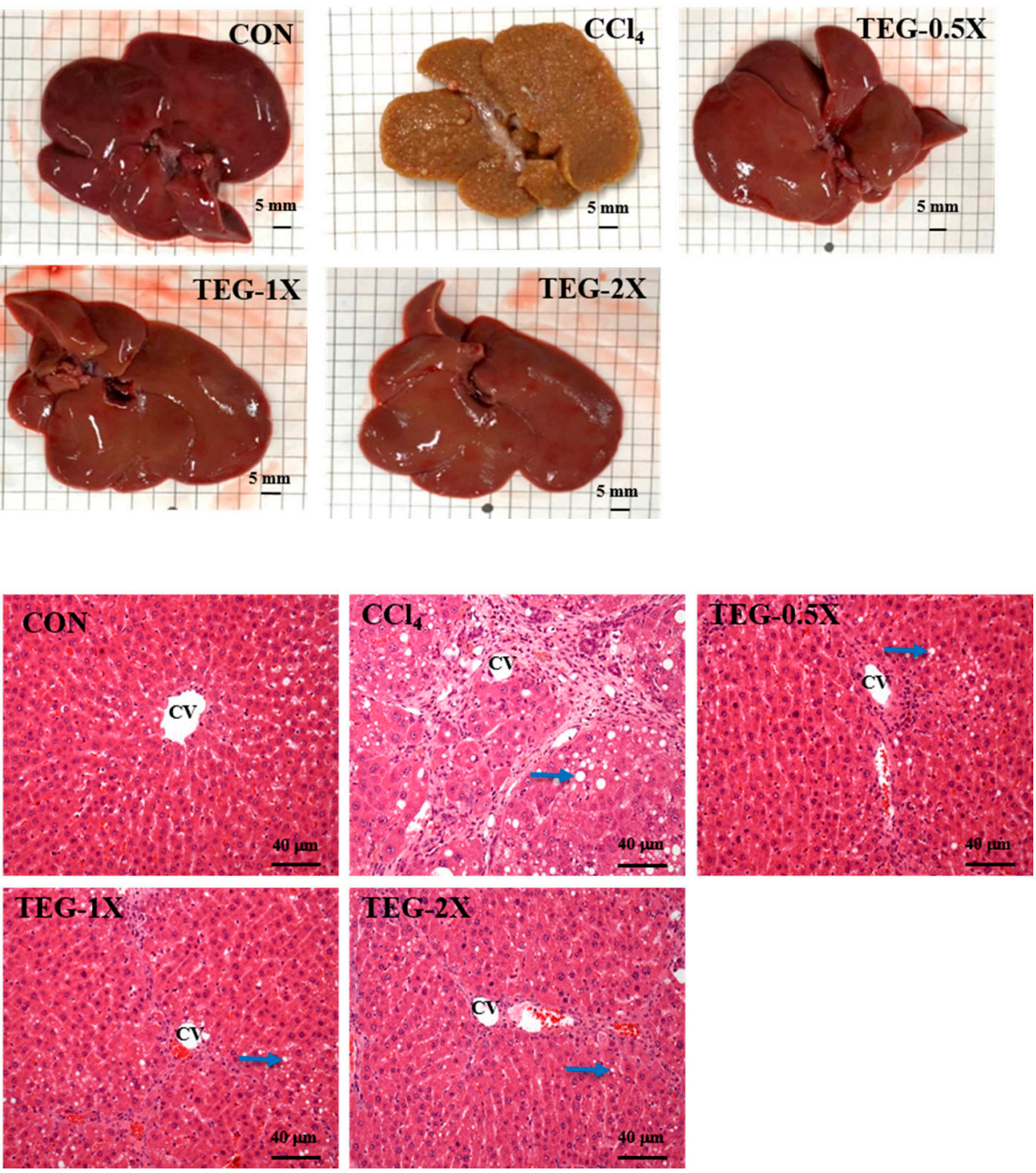

(C)
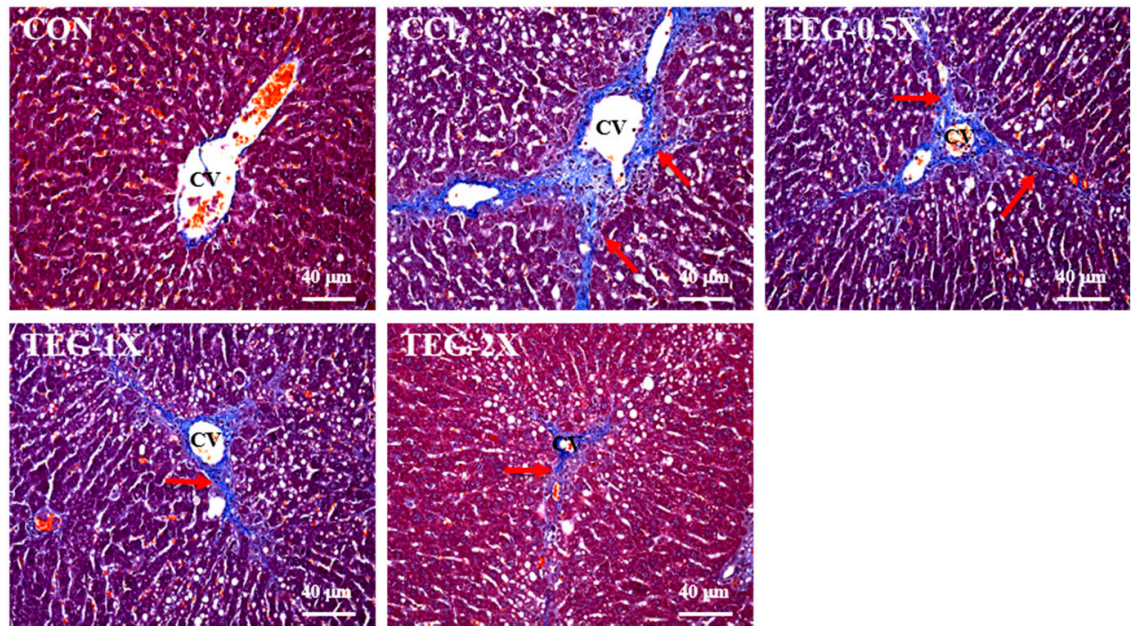

Figure 5. Characteristic livers after traditional essence of ginseng (TEG) supplementation with carbon tetrachloride $\left(\mathrm{CCl}_{4}\right)$-induced liver damage: (A) macroscopic characteristic of livers in $\mathrm{CON}$, $\mathrm{CCl}_{4}$, and TEG supplemented groups (CCl , TEG-0.5X, TEG-1X, and TEG-2X) (Scale bar, $5 \mathrm{~mm}$ ). (B) H\&E stain of liver tissues in $\mathrm{CON}, \mathrm{CCl}_{4}$, and TEG supplemented groups $\left(\mathrm{CCl}_{4}\right.$, TEG-0.5X, TEG-1X, and TEG-2X). CV: central vein, blue arrows mark vacuoles caused by steatosis (magnification: $\times 200$; scale bar: $40 \mu \mathrm{m}$ ). (C) Masson's trichrome stain of liver tissues in CON, $\mathrm{CCl}_{4}$, and TEG supplemented groups ( $\mathrm{CCl}_{4}$, TEG-0.5X, TEG-1X, and TEG-2X). CV: central vein, red arrows mark collagen fibers. (magnification: $\times 200$, scale bar: $40 \mu \mathrm{m}$ ). 
Table 3. Effects of traditional essence of ginseng (TEG) on hepatic histopathology scores in rats with carbon tetrachloride $\left(\mathrm{CCl}_{4}\right)$-induced liver damage.

\begin{tabular}{|c|c|c|c|c|c|}
\hline Group & Fatty Changes & $\begin{array}{c}\text { Bile Duct } \\
\text { Hyperplasia }\end{array}$ & $\begin{array}{l}\text { Inflammatory } \\
\text { Cell Infiltration }\end{array}$ & Necrosis & Fibrosis \\
\hline $\mathrm{CON}$ & $0.00 \pm 0.00^{\mathrm{a}}$ & $0.00 \pm 0.00^{\mathrm{a}}$ & $0.00 \pm 0.00^{\mathrm{a}}$ & $0.00 \pm 0.00^{\mathrm{a}}$ & $0.00 \pm 0.00^{a}$ \\
\hline $\mathrm{CCl}_{4}$ & $2.38 \pm 1.06^{c}$ & $2.00 \pm 0.53^{c}$ & $2.13 \pm 0.83^{c}$ & $1.75 \pm 0.71^{\mathrm{c}}$ & $1.63 \pm 0.74^{\mathrm{c}}$ \\
\hline TEG-0.5X & $1.13 \pm 0.83^{b}$ & $1.00 \pm 0.53^{b}$ & $1.63 \pm 0.74^{b}$ & $1.13 \pm 0.35^{b}$ & $1.00 \pm 0.76^{b c}$ \\
\hline TEG-1X & $1.13 \pm 0.64^{b}$ & $1.25 \pm 0.46^{b}$ & $1.50 \pm 0.76^{b}$ & $1.00 \pm 0.53^{b}$ & $1.13 \pm 0.64 b c$ \\
\hline TEG-2X & $1.38 \pm 0.92^{b}$ & $1.00 \pm 0.76^{b}$ & $1.25 \pm 0.46^{b}$ & $1.13 \pm 0.64^{b}$ & $0.75 \pm 0.71^{b}$ \\
\hline
\end{tabular}

Values are presented as mean $\pm \mathrm{SD}$ for $n=8$. Values in a column with the same letters $(\mathrm{a}, \mathrm{b}, \mathrm{c})$ do not significantly differ at $p<0.05$ according to one-way ANOVA with the Cochran-Armitage test and trend analysis. CON, control group. $\mathrm{CCl}_{4}, \mathrm{CCl}_{4}$, administration only. TEG-0.5X, $\mathrm{CCl}_{4}$ administration with 0.5 times the daily recommended dosage of the TEG. TEG-1X, $\mathrm{CCl}_{4}$ administration with daily recommended dosage of TEG. TEG-2X, $\mathrm{CCl}_{4}$ administration with two times the daily recommended dosage of TEG.

\section{Discussion}

The results show that the TEG contained a high level of ginsenoside Rg2. After supplementation with TEG for nine consecutive weeks and $\mathrm{CCl}_{4}$-induced liver injury for eight weeks, the concentrations of liver injury biochemical indicators [16] in animal serum decreased significantly, and, in liver tissue, the antioxidant activity significantly improved and the accumulation of lipids decreased. Pathological sections showed reduced liver lipid accumulation and fibrosis.

In the $\mathrm{CCl}_{4}$-induced chemical liver injury model, AST and ALT are important liver injury markers. In particular, AST, known as the main enzyme in hepatocytes, exists in the blood at a level about 3000 -fold higher than that in liver cells when $1 \%$ of hepatocytes are damaged [17,18]. Medicinal plants have significant therapeutic value, and plant natural products or extracts can be associated with the infiltration of inflammatory neutrophils and macrophages to counter pathological changes, such as lipid infiltration, autophagy, and apoptosis [19]. Especially in hepatic protection, the medicinal herb Terminalia belerica Roxb has been observed to reduce glutathione levels in carbon tetrachloride-affected rats to improve hepatic function [20]. In the traditional system of Chinese medicine, the extracts of Ginkgo biloba leaves have been used to protect neurons, and they have also been proven to have a hepatoprotective effect against $\mathrm{CCl}_{4}$-induced hepatotoxicity in rats. Their effect is related to the inhibition of lipid peroxidative processes, and they further prevent GSH depletion that begins when G. biloba phytosomes exert their antioxidant activity by a two-fold action [21].

Ginseng is also a well-known traditional herb. Previous studies have shown that pre-treatment with $P$. ginseng CA Meyer can reverse liver toxicity induced by benzo $[\alpha]$ pyrene. Elevated plasma ALT and AST levels can be decreased by revised GSH content and glutathione S-transferase activity [22]. Ginsenosides are the major active ingredients of ginseng. They have been reported to have neuroprotective effects on SOD and GPX by preventing lipid peroxidation as a result of oxidative stress [23]. It may be due to the mitochondrial membrane being stable and maintaining the mitochondrial structure, leading to complete retention of mitochondrial functions. During energy respiration and oxidative phosphorylation, numerous electrons leak out from the uncoupled electron transport chain $[24,25]$. When the reactive oxygen species level is high, free radical scavengers are depleted and attack the antioxidant system, leading to excessive oxidative stress in the body [26]. Therefore, protecting the integrity of liver mitochondria by stabilizing the structure and function is important to maintaining the normal function of cells, resisting reduced ROS formation, and protecting against $\mathrm{CCl}_{4}$ —induced cytotoxicity [27].

According to previous studies, ischemia-reperfusion might be related to cell apoptosis $[28,29]$. However, ginsenoside $\mathrm{Rg} 2$ can increase cell antioxidants by decreasing lipid peroxidation (e.g., the excessive production of malondialdehyde and nitric oxide) with the protein expression levels of calpain II, caspase3, and beta-amyloid1-40 in PC12 cells with introduced glutamate [30]. Ginsenoside $\mathrm{Rg} 2$ inhibits the influx of $\mathrm{Na}^{+}$through the channels by acting on nicotinic acetylcholine receptor-operated cation channels, consequently reducing both the $\mathrm{Ca}^{2+}$ influx and catecholamine 
secretion in chromaffin cells [31]. This process can down-regulate the expression of pro-apoptotic factors BAX and P53 and up-regulate the BCL2 family of proteins and mitochondrial hsp70 (HSP70) to maintain mitochondrial function. These results demonstrate that ginsenoside $\mathrm{Rg} 2$ has a neuroprotective effect by preventing cell apoptosis [11,31-33]. Liver fibrosis is a physiological response to chronic or iterative liver injury and can progress to cirrhosis over time [34]. Approximately $45 \%$ of all cirrhosis deaths are related to fibroproliferative diseases [35]. Extracellular matrix (ECM) turnover and its production affect cell development and lead to complications of cirrhosis by indirect complex matrix biology and provide an early signal to generate collagen [36]. Accumulating studies have indicated that the Nrf2 gene in hepatocytes can regulate the antioxidant and inflammatory response factors that promote liver fibrosis by blocking downstream signaling pathways [37-40], and the antioxidant activity decreases liver fibrosis [41]. Our research results show that the antioxidant Rg2 in TEG may reduce oxidative stress and keep cell function intact without apoptosis, and, furthermore, reduce the occurrence of fibrosis caused by chemical liver injury.

\section{Conclusions}

The results of this study show that supplementation with $0.5 \mathrm{X}, 1 \mathrm{X}$, and $2 \mathrm{X}$ doses of traditional essence of ginseng with a high content of ginsenoside $\mathrm{Rg} 2$ for nine consecutive weeks affected multiple clinical liver-function-related indicators, suggesting that the combination of increasing the antioxidant status, reducing fat accumulation, and inhibiting inflammation can reduce liver damage. This supplementation can help reduce aspartate aminotransferase and alanine aminotransferase in serum, reduce serum triglyceride and total cholesterol, and increase antioxidant status to achieve a protective function. We also observed that the TEG dose dependently inhibited the rise of AST, ALT, TC, and TG, and restored the levels of antioxidant enzymes, i.e., GSH, GPX, GR, SOD, and CAT, as well as TC and TG in liver contents of $\mathrm{CCl}_{4}$-treated rats. In conclusion, these results suggest a protective effect of TEG in rats against $\mathrm{CCl}_{4}$-induced liver injuries.

Author Contributions: Y.-J.H. and C.-C.H. designed the experiments. M.-C.L. and Y.-J.H. conducted the laboratory experiments. M.-C.L., Y.-J.H., and C.-C.H. contributed reagents, materials, and analysis platforms. Y.-J.H. and C.-C.H. analyzed the data. C.-Y.W., Y.-J.H., and C.-C.H. interpreted the results, prepared the figures, wrote the manuscript, and revised the manuscript. All authors have read and agreed to the published version of the manuscript.

Funding: This study was funded by the University-Industry Cooperation Fund, National Taiwan Sport University, Taoyuan, Taiwan (NTSU No.1071027).

Acknowledgments: The authors are grateful to the graduate students at the Sport Nutrition Laboratory, National Taiwan Sport University, for their technical assistance in conducting the animal experiments.

Conflicts of Interest: The authors declare no conflict of interest.

\section{References}

1. Gu, X.; Manautou, J.E. Molecular mechanisms underlying chemical liver injury. Expert Rev. Mol. Med. 2012, 14, e4. [CrossRef] [PubMed]

2. Hoekstra, L.; Graaf, W.; Nibourg, A.A.; Heger, M.; Bennink, J.; Stieger, B.; Gulik, T.M. Physiological and biochemical basis of clinical liver function tests: A review. Ann. Surg. 2013, 257, 27-36. [CrossRef] [PubMed]

3. Cichoż-Lach, H.; Michalak, A. Oxidative stress as a crucial factor in liver diseases. World J. Gastroenterol. 2014, 20, 8082. [CrossRef] [PubMed]

4. Weber, L.W.D.; Boll, M.; Stampfl, A. Hepatotoxicity and mechanism of action of haloalkanes: Carbon tetrachloride as a toxicologicalmodel. Crit. Rev. Toxicol. 2003, 33, 105-136. [CrossRef] [PubMed]

5. Lombardi, B.; Ugazio, G.; Raick, A.N. Choline-deficiency fatty liver: Relation of plasma phospholipids to liver triglycerides. Am. J. Physiol. 1966, 210, 31-36. [CrossRef] [PubMed]

6. Yu, H.; Zhao, J.; You, J.; Li, J.; Ma, H.; Chen, X. Factors influencing cultivated ginseng (Panax ginseng CA Meyer) bioactive compounds. PLoS ONE 2019, 14, e0223763. [CrossRef]

7. Kitts, D.D.; Hu, C. Efficacy and safety of ginseng. Public Health Nutr. 2000, 3, 473-485. [CrossRef] 
8. Ma, Y.C.; Zhu, J.; Benkrima, L.; Luo, M.; Sun, L.; Sain, S.; Kont, K.; Yu, Y.; Carcasson, C. A comparative evaluation of ginsenosides in commercial ginseng products and tissue culture samples using HPLC. J. Herbs Spices Med. Plants 1996, 3, 41-50. [CrossRef]

9. Yang, C.S.; Ko, S.R.; Cho, B.G.; Shin, D.M.; Yuk, J.M.; Li, S.; Kim, J.M.; Evans, R.M.; Jun, J.S.; Song, D.K.; et al. The ginsenoside metabolite compound $\mathrm{K}$, a novel agonist of glucocorticoid receptor, induces tolerance to endotoxin-induced lethal shock. J. Cell. Mol. Med. 2008, 12, 1739-1753. [CrossRef]

10. Lin, S.Y.; Xu, D.; Du, X.X.; Ran, C.L.; Xu, L.; Ren, S.J.; Tang, Y.T.; Li, Z.Y.; Chang, L.H.; Zhi, X.Y.; et al. Protective effects of salidroside against carbon tetrachloride $\left(\mathrm{CCl}_{4}\right)$-induced liver injury by initiating mitochondria to resist oxidative stress in mice. Int. J. Mol. Sci. 2019, 20, 3187. [CrossRef]

11. Zhang, G.; Liu, A.; Zhou, Y.; San, X.; Jin, T.; Jin, Y. Panax ginseng ginsenoside-Rg2 protects memory impairment via anti-apoptosis in a rat model with vascular dementia. J. Ethnopharmacol. 2008, 115, 441-448. [CrossRef] [PubMed]

12. Huang, W.C.; Chiu, W.C.; Chuang, H.L.; Tang, D.W.; Lee, Z.M.; Wei, L.; Chen, F.A.; Huang, C.C. Effect of curcumin supplementation on physiological fatigue and physical performance in mice. Nutrients 2015, 7, 905-921. [CrossRef] [PubMed]

13. Hamza, A.A. Ameliorative effects of Moringa oleifera Lam seed extract on liver fibrosis in rats. Food Chem. Toxicol. 2010, 48, 345-355. [CrossRef] [PubMed]

14. Chiu, W.C.; Huang, Y.L.; Chen, Y.L.; Peng, H.C.; Liao, W.H.; Chuang, H.L.; Chen, J.R.; Yang, S.C. Synbiotics reduce ethanol-induced hepatic steatosis and inflammation by improving intestinal permeability and microbiota in rats. Food Funct. 2015, 6, 1692-1700. [CrossRef]

15. Ghadir, M.R.; Riahin, A.A.; Havaspour, A.; Nooranipour, M.; Habibinejad, A.A. The relationship between lipid profile and severity of liver damage in cirrhotic patients. Hepat. Mon. 2010, 10, 285.

16. Drotman, R.B.; Lawhorn, G.T. Serum enzymes as indicators of chemically induced liver damage. Drug Chem. Toxicol. 1978, 1, 163-171. [CrossRef] [PubMed]

17. Shyur, L.F.; Huang, C.C.; Hsu, Y.Y.; Cheng, Y.W.; Yang, S.D. A sesquiterpenol extract potently suppresses inflammation in macrophages and mice skin and prevents chronic liver damage in mice through JNK-dependent HO-1 expression. Phytochemistry 2011, 72, 391-399. [CrossRef]

18. Sookoian, S.; Pirola, C.J. Liver enzymes, metabolomics and genome-wide association studies: From systems biology to the personalized medicine. World J. Gastroenterol. 2015, 21, 711-725. [CrossRef] [PubMed]

19. Li, F.S.; Weng, J.K. Demystifying traditional herbal medicine with modern approach. Nat. Plants 2017, 3, 17109. [CrossRef]

20. Jadon, A.; Bhadauria, M.; Shukla, S. Protective effect of Terminalia belerica Roxb. and gallic acid against carbon tetrachloride induced damage in albino rats. J. Ethnopharmacol. 2007, 109, 214-218. [CrossRef]

21. Naik, S.R.; Panda, V.S. Antioxidant and hepatoprotective effects of Ginkgo biloba phytosomes in carbon tetrachloride-induced liver injury in rodents. Liver Int. 2007, 27, 393-399. [CrossRef] [PubMed]

22. Gum, S.I.; Jo, S.J.; Ahn, S.H.; Kim, S.G.; Kim, J.T.; Shin, H.M.; Cho, M.K. The potent protective effect of wild ginseng (Panax ginseng CA Meyer) against benzo $[\alpha]$ pyrene-induced toxicity through metabolic regulation of CYP1A1 and GSTs. J. Ethnopharmacol. 2007, 112, 568-576. [CrossRef] [PubMed]

23. Demir, I.; Kiymaz, N.; Gudu, B.O.; Turkoz, Y.; Gul, M.; Dogan, Z.; Demirtas, S. Study of the neuroprotective effect of ginseng on superoxide dismutase (SOD) and glutathione peroxidase (GSH-Px) levels in experimental diffuse head trauma. Acta Neurochir. 2013, 155, 913-922. [CrossRef] [PubMed]

24. Zorov, D.B.; Filburn, C.R.; Klotz, L.O.; Zweier, J.L.; Sollott, S.J. Reactive oxygen species (ROS)-induced ROS release: A new phenomenon accompanying induction of the mitochondrial permeability transition in cardiac myocytes. J. Exp. Med. 2000, 192, 1001-1014. [CrossRef]

25. Lee, J.; Giordano, S.; Zhang, J. Autophagy, mitochondria and oxidative stress: Cross-talk and redox signalling. Biochem. J. 2012, 441, 523-540. [CrossRef]

26. Sinha, K.; Das, J.; Pal, P.B.; Sil, P.C. Oxidative stress: The mitochondria-dependent and mitochondriaindependent pathways of apoptosis. Arch. Toxicol. 2013, 87, 1157-1180. [CrossRef]

27. Ulicná, O.; Greksák, M.; Vancová, O.; Zlatos, L.; Galbavý, S.; Bozek, P.; Nakano, M. Hepatoprotective effect of rooibos tea (Aspalathus linearis) on $\mathrm{CCl}_{4}$-induced liver damage in rats. Physiol. Res. 2003, 52, 461-466.

28. Ferrer, I.; Friguls, B.; Dalfo, E.; Justicia, C.; Planas, A.M. Caspase- 'dependent and caspase-independent signalling of apoptosis in the penumbra following middle cerebral artery occlusion in the adult rat. Neuropathol. Appl. Neurobiol. 2003, 29, 472-481. [CrossRef] 
29. Greco, R.; Amantea, D.; Blandini, F.; Nappi, G.; Bagetta, G.; Corasaniti, M.T.; Tassorelli, C. Neuroprotective effect of nitroglycerin in a rodent model of ischemic stroke: Evaluation of Bcl-2 expression. Int. Rev. Neurobiol. 2007, 82, 423-435.

30. Li, N.; Liu, B.; Dluzen, D.E.; Jin, Y. Protective effects of ginsenoside $\operatorname{Rg}(2)$ against glutamate-induced neurotoxicity in PC12 cells. J. Ethnopharmacol. 2007, 111, 458-463. [CrossRef]

31. Tachikawa, E.; Kudo, K.; Kashimoto, T.; Takahashi, E. Ginseng saponins reduce acetylcholine-evoked $\mathrm{Na}^{+}$ influx and catecholamine secretion in bovine adrenal chromaffin cells. J. Pharmacol. Exp. Ther. 1995, 273, 629-636. [PubMed]

32. Miyashita, T.; Reed, J.C. Tumor suppressor p53 is a direct transcriptional activator of the human bax gene. Cell 1995, 80, 293-299. [PubMed]

33. Nataraj, A.J.; Trent, J.C., II; Ananthaswamy, H.N. p53 gene mutations and photocarcinogenesis. J. Photochem. Photobiol. C. 1995, 62, 218-230. [CrossRef] [PubMed]

34. Li, J.; Wang, Y.; Ma, M.; Jiang, S.; Zhang, X.; Zhang, Y.; Wang, Y. Autocrine CTHRC1 activates hepatic stellate cells and promotes liver fibrosis by activating TGF- $\beta$ signaling. EBioMedicine 2019, 40, 43-55. [CrossRef]

35. Schuppan, D.; Ashfaq-Khan, M.; Yang, A.T.; Kim, Y.O. Liver fibrosis: Direct antifibrotic agents and targeted therapies. Matrix Biol. 2018, 68, 435-451. [CrossRef]

36. Karsdal, M.A.; Manon-Jensen, T.; Genovese, F.; Kristensen, J.H.; Nielsen, M.J.; Sand, J.M.B.; Hansen, N.U.B.; Bay-Jensen, A.C.; Bager, C.L.; Krag, A.; et al. Novel insights into the function and dynamics of extracellular matrix in liver fibrosis. Am. J. Physiol. Gastrointest. Liver Physiol. 2015, 308, G807-G830. [CrossRef]

37. Shanmugam, G.; Challa, A.K.; Litovsky, S.H.; Devarajan, A.; Wang, D.; Jones, D.P.; Darley-Usmar, V.M.; Rajasekaran, N.S. Enhanced Keap1-Nrf2 signaling protects the myocardium from isoproterenol-induced pathological remodeling in mice. Redox Biol. 2019, 27, 101212. [CrossRef]

38. Yamamoto, M.; Kensler, T.W.; Motohashi, H. The KEAP1-NRF2 system: A thiol-based sensor-effector apparatus for maintaining redox homeostasis. Physiol. Rev. 2018, 98, 1169-1203. [CrossRef] [PubMed]

39. Lu, C.; Xu, W.; Zheng, S. Nrf2 activation is required for curcumin to induce lipocyte phenotype in hepatic stellate cells. Biomed. Pharmacother. 2017, 95, 1-10. [CrossRef]

40. Rehman, H.; Liu, Q.; Krishnasamy, Y.; Shi, Z.; Ramshesh, V.K.; Haque, K.; Schnellmann, R.G.; Murphy, M.P.; Lemasters, J.J.; Rockey, D.C.; et al. The mitochondria-targeted antioxidant MitoQ attenuates liver fibrosis in mice. J. Physiol. 2016, 8, 14 .

41. Lyu, H.; Wang, H.; Li, L.; Zhu, J.; Chen, F.; Chen, Y.; Liu, C.; Fu, J.; Yang, B.; Zhang, Q.; et al. Hepatocyte-specific deficiency of Nrf2 exacerbates carbon tetrachloride-induced liver fibrosis via aggravated hepatocyte injury and subsequent inflammatory and fibrogenic responses. Free Radic. Biol. Med. 2020, 150, 136-147. [CrossRef] [PubMed]

Publisher's Note: MDPI stays neutral with regard to jurisdictional claims in published maps and institutional affiliations.

(C) 2020 by the authors. Licensee MDPI, Basel, Switzerland. This article is an open access article distributed under the terms and conditions of the Creative Commons Attribution (CC BY) license (http://creativecommons.org/licenses/by/4.0/). 